\title{
CONCEITOS DE MULHERES SOBRE SUA MENSTRUAÇÃO*
}

\author{
Márcia Yuri Shinohara** \\ Lucila Coca Bezerra ** \\ Ângela Megumi Takagi"***
}

\begin{abstract}
RESUMO: Dando prosseguimento às pesquisas anteriores realizadas pelo Núcleo de Assistência para o Autocuidado da Mulher (NAAM) sobre aspectos relativos à menstruação, desenvolvemos um trabalho que estudou os conceitos de 705 mulheres sobre sua menstruação. Foram utilizadas informações do banco de dados do NAAM, obtidos na aplicação do Histórico de Saúde da Mulher no Município de Vargem Grande Paulista. O conceito mais relatado pelas mulheres foi o Normal. Isto talvez explique os dados obtidos em trabalhos anteriores, onde muitas mulheres nada fazem para aliviar os sintomas dolorosos da menstruação. O acesso a estes conceitos próprios é importante para elaborar uma assistência de enfermagem de qualidade respeitando as crenças e valores dentro da cultura das mulheres.
\end{abstract}

ABSTRACT: Procceding earlier researches achieved by Assistance Nucleus for the Self-care of Woman (ANSW) about menstruation aspects, we developed a work that studied concepts of 705 women about their menstruation. Bank of data from the ANSW gave informations obtained in employment at the Historic of Woman's Health in Vargem Grande Paulista. The concept more related was normal. Perhaps, it explains the data obtained in earlier works, where many women do nothing to relieve the painful symptoms of menstruation. The access to these proper concepts is important to elaborate a nursing assistance with quality, respecting convictions and valuables within the women's culture.

UNITERMOS: Menstruaçåo - Saúde da Mulher - História Oral.

\section{INTRODUÇÃO}

O presente estudo é um seguimento dos trabalhos realizados pelo Núcleo de Assistência para o Autocuidado da Mulher - NAAM, sobre o tema menstruação. Observamos que nesses trabalhos(7), as mulheres atendidas pelo NAAM relatavam sintomatologia dolorosa durante o período menstrual e executam ações de autocuidado para alívio destes sintomas, sem necessariamente procurar o serviço profissional, por provavelmente conviverem com estes problemas. Decidimos, então aprofundar o conhecimento sobre a menstruação, na tentativa de compreender melhor essas ações de autocuidado na nossa população.

COMFORT e COMFORT(3) citam que o processo da menstruação sempre intrigou a civilização humana. Associava-se o período da menstruação à magia, acreditando-se que, se uma mulher menstruada fizesse um pão, a massa não cresceria; que se fizesse uma geléia, ela jamais ficaria no ponto, e assim por diante.

O Antigo Testamento da BÍBLIA sagrada(1) diz: A mulher que no tempo ordinário sofre incomodo, será separada durante sete dias. Todo

Trabalho apresentado como Tema Livre no $45^{\circ}$ Congresso Brasileiro de Enfermagem. Olinda-Recife, 28 de novembro a 3 de dezembro de 1994.

** Alunas de graduaçáo da Escola de Enfermagem da Universidade de Sáo Paulo. Membros do Núcleo de Assistência para o Autocuidado da Mulher (NAAM).

*** Enfermeira Obstétrica. Membro do NAAM. 
que a tocar, será impuro até a tarde.

SNOWDEN e CHRISTIAN(6) citam as diferentes visões em algumas culturas. Para o islamismo, a mulher é considerada impura e não é permitido aproximar-se dela até que esteja limpa, novamente. Em países como Egito, Índia, Jamaica, lugoslávia e Filipinas é desaconselhável a visita às mulheres menstruadas por amigos ou parentes, principalmente para gestantes e puérperas, pois a mulher menstruada é considerada uma ameaça a saúde reprodutiva e fértil destas. No Egito a mulher menstruada é mais susceptivel aos espíritos sobrenaturais, passando por crises idênticas ao nascimento de uma criança. Em grande parte da Índia, Filipinas e Egito as mulheres menstruadas evitam os campos para não prejudicarem a atividade agrícola.

WEIL (8) analisa o fluxo menstrual colocando-o dentro de um mundo viscoso e pegajoso. A viscosidade é objeto de repulsão desde a mais tenra idade. O pegajoso escapa às três categorias que são: sólido, líquido e gasosos, situandose entre o sólido e o líquido. SARTRE citado por WEIL (8) afirma que nós consideramos a viscosidade como uma forma ignóbil da existência, estando ela assim relacionada ao fluxo menstrual, criando uma imagem repulsiva.

BUCKLEY e GOTTLIEB(2) mostram que os valores e significados do tabu da menstruação não existem isolados, mas ocorrem dentro de um contexto, especialmente relacionados à religião. O significado e o valor da menstruação, de uma certa cultura, devem ser determinados no local, e não podem ser descritos com base em conceitos pré-estabelecidos ou originados de outras culturas.

De acordo com SNOWDEN e CHRISTIAN(6), o fator psicossocial tem um papel importante na atitude frente à menstruação. A mulher menstruada é vista pela sociedade como mal humorada, irritada. A menstruação não é simplesmente um processo fisiológico, mas está ligado a variáveis psicológicas sociais e culturais. Como todas as mulheres menstruam, elas estão sujeitas aos mesmos tabus culturais de restrição, segregação e discriminação. Contudo, a mulher individualmente é capaz de diferenciar cada sangramento nas dimensões de quantidade, duração e forma, o qual ocorre num certo intervalo de tempo e regularidade. Juntamente com as características sociais do próprio sangra- mento, a menstruação tem um significado individual para cada mulher. Assim, a mulher tem duas percepções do sangramento: uma da sua real experiência e outra como um membro dentro da sociedade a qual sofre influências dos significados que são atribuídos à menstruação. A interação destas duas percepções irá afetar as atitudes e a descrição do evento.

Ao estudarmos as questões ligadas à menstruação, chamou-nos a atenção que no trabalho realizado por TAKAGI, BENITES e SHINOHA$R A(7)$, um terço das mulheres de uma comunidade, apesar de apresentarem sintomas dolorosos no período menstrual, nada faziam para alívio destes sintomas. É também relevante a colocação feita por SNOWDEN e CHRISTIAN(6), de que as atitudes das mulheres em relação à menstruação são afetadas pela interação das suas percepções sobre este acontecimento em suas vidas, sendo a compreensão deste fato de grande importância para o planejamento de uma intervenção de enfermagem mais adequada e efetiva. Principalmente quando estabelecemos a nossa atuação tendo como referencial a teoria de OREM(5), na qual o indivíduo é visto como tendo a capacidade de praticar atividades em seu próprio benefício, para manutenção contínua de sua vida, saúde e bemestar. Esta teoria tem como núcleo a habilidade inata que o homem tem para cuidar de si proprio, sendo esta influenciada por práticas, crenças e hábitos, que fazem parte da cultura e do grupo a que o individuo pertence.

Desta forma, sentimos a necessidade de aprofundar nossos conhecimentos quanto aos conceitos das mulheres sobre sua menstruação, sendo este o objetivo deste trabalho.

\section{MATERIAL E MÉTODO}

Em 1986 o Núcleo de Assistência para o Auto cuidado da Mulher (NAAM), iniciou suas atividades de assistência que compreendem: consulta de enfermagem, realização de grupo de orientação e visitas domiciliares no município de Vargem Grande Paulista, complementada com atividades de pesquisa desenvolvidas com suporte logístico da Escola de Enfermagem da Universidade de São Paulo.

Para consulta de enfermagem é utilizado instrumento de coleta de dados, o histórico da 
saúde da mulher, que se divide em três partes: I. Histórico Auto-Aplicado com questőes abertas, II. Entrevista com questões semi-estruturadas, III. Exame Físico (Anexo).

A parte I é preenchida pela própria mulher, desde que ela seja capaz de ler e escrever. Diante de sua impossibilidade, essa parte é preenchida com a ajuda de um dos integrantes do NAAM. As parte II e III são preenchidas pelos integrantes do núcleo, a partir das respostas e achados obtidos na consulta.

Para realização do presente estudo foram utilizadas, a partir do banco de dados do NAAM, as respostas da questão 08 da parte II: $O$ que voce acha que săo as regras?

\section{População}

A população constitui-se de 705 mulheres que procuraram o NAAM para realização de exame de prevenção de câncer ginecológico no período de 1988 a 1991. Foram encaminhadas por médicos da própria unidade básica de saúde de Vargem Grande Paulista ou compareceram por iniciativa própria.

\section{Local de Estudo}

O trabalho foi realizado no município de Vargem Grande Paulista, a $65 \mathrm{~km}$ da cidade de São Paulo, no chamado cinturăo verde de São Paulo. Apresenta uma população estimada de 35.000 habitantes atendidos em quatro unidades básicas de saúde.

\section{Definição:de Termos}

Para melhor estudarmos os conceitos da mulheres sobre sua menstruação resolvemos agrupá-las em categorias. São elas: Normal, Saúde, Limpeza, Ovulação, Boa/Ruim, Outros e Não responderam.

Normal: para esta categoria, utilizamos a definição de COMFORT e COMFORT(3), em que menstruação é um processo de desenvolvimento da mulher, desde a puberdade até por volta dos 50 anos com desprendimento da camada de células uterinas e sangramento pela vagina. Tem ciclo aproximado de 28 dias, sendo que se interrompe durante a gestação.

Dividimos essa categoria, Nomal, em sub- categorias: Feminilidade, Fisiológico e Reprodução.

Feminilidade: incluimos nesta sub-categoria as mulheres que relataram a menstruação como próprio da mulher, seu caráter, seu modo de ser e pensar ou viver, ressaltando o ritual de passagem de menina para moça, com o início da menstruação até o seu témino com a menopausa(4).

Fisiologico: fazem parte desta sub-categoria respostas relacionadas ao desprendimento da camada de células uterinas, com sangramento pela vagina, que ocorre num ciclo de aproximadamente de $\mathbf{2 8}$ dias, com em média 5 dias de duração.

Reproduçăo: nesta sub-categoria inserimos respostas sobre gravidez e geração de filhos.

Saúde: para esta categoria, consideramos as respostas em que menstruação é o bem estar físico e mental, sendo que sua ausência acarreta problemas de saúde.

A categoria Saúde foi subdividida em: Integral (do organismo como um todo) ou Parcial (como exemplo a saúde mental).

Limpeza: define-se essa categoria como expulsão de sujeira ou sangue sujo do organismo da mulher e a purificação do corpo.

Esta categoria foi subdividida em: Limpeza global (do corpo como um todo) ou Limpeza local (de uma determinada parte do corpo, como por exemplo, do útero).

Ovulação: nesta categoria inserimos respostas onde as mulheres relatam a saída do óvulo na menstruação.

Boa/Ruim: foram incluidas nesta categoria respostas onde as mulheres expressaram sua menstruação como uma coisa boa, relacionado-a com o prazer sexual ou como uma coisa ruim, que incomoda.

Outros: inserimos nesta as respostas que não foram incluídas em nenhuma das categorias anteriores.

Não responderam: foram incluidas nesta, as mulheres que não sabiam referir sobre as regras e as que não responderam adequaciamente à pergunta. Entre estas, haviam respostas relacionadas aos sintomas da menstruação, como por exemplo: cefaléia, cólica,que fazem parte do trabalho anterior. 


\section{RESULTADOS E DISCUSSÃO}

Tabela 1: Distribuição em categorias dos diferentes conceitos das mulheres sobre sua menstruaçăo. NAAM, São Paulo, 1993.

\begin{tabular}{l|r|r}
\hline \multicolumn{1}{c|}{ CATEGORIAS } & \multicolumn{1}{c|}{ No $^{\circ}$} & \multicolumn{1}{c}{$\%$} \\
\hline NORMAL & 296 & 36,5 \\
\hline SAÚDE & 84 & 10,3 \\
\hline LIMPEZA & 77 & 9,5 \\
\hline OVULAÇÃO & 23 & 2,8 \\
\hline BOA/RUIM & 13 & 1,6 \\
\hline OUTROS & 09 & 1,1 \\
\hline NÅ RESPONDERAM & 310 & 38,2 \\
\hline TOTAL* & 812 & 100,0 \\
\hline
\end{tabular}

- Algumas mulheres apresentaram mais de uma resposta, portanto, o número total de respostas é superior ao total de mulheres do estudo.

A tabela 1 apresenta $812(100 \%)$ respostas relacionadas aos conceitos das mulheres frente sua menstruação. A maior incidência foi da categoria Normal, com 296 (36,5\%) respostas, sendo que essa categoria foi dividida em sub-categorias Feminilidade, Fisiologico e Reproduçăo. Seguida desta categoria 84 (10,3\%) mulheres deram respostas relacionadas à Saúde; nesta categoria a mulher relata a Saúde como sendo Integral ou Parcial. Com um total de 77 (9,5\%) respostas surge a categoria Limpeza, subdividida em Limpeza global ou local. A categoria Ovulação aparece com $23(2,8 \%)$ respostas, seguida da categoria Boa/Ruim com $13(1,6 \%)$ respostas. Apareceram $9(1,1 \%)$ respostas que não se encaixaram em nenhuma das categorias acima citadas.

Verificou-se que na categoria Não responderam, $310(38,3 \%)$ mulheres não apresentaram respostas, ou as apresentadas não tinham nenhuma relação com a pergunta. Esse fato pode estar relacionado às escassas informações dadas a estas mulheres em relação a sua menstruação, devido à educação sexual ser pouco discutida nas escolas, dentro da própria família e nos postos de saúde, que não se preocupam em passar informação às mulheres. Englobamos também, nesta categoria, a ausência de respostas devido ao preenchimento incompleto do Histórico pelos membros do NAAM.
Tabela 2: Distribuição dos conceitos das muIheres sobre sua menstruaçåo inseridas na Categoria Normal e suas respectivas sub-categorias. NAAM, São Paulo, 1993.

\begin{tabular}{l|l|r|r}
\hline CATEGORIA & SUB-CATEGORIA & \multicolumn{1}{|c|}{ No $^{\circ}$} & \multicolumn{1}{c}{$\%$} \\
\hline \multirow{3}{*}{ NORMAL } & FEMINILIDADE & 143 & 48,3 \\
\cline { 2 - 4 } & REPRODUÇÃO & 77 & 26,0 \\
\cline { 2 - 4 } & FISIOLÓGICO & 76 & 25,7 \\
\multirow{2}{*}{ TOTAL } & & 296 & 100,0 \\
\hline
\end{tabular}

Diante da tabela 2 , verificamos um total de $296(100 \%)$ respostas que apareceram na categoria Normal, sendo que $143(48,3 \%)$ respostas compőem a sub-categoria Feminilidade, 77 $(26,0 \%)$ respostas pertencem a subcategoria Reproduçăo e $76(25,7 \%)$ respostas são da subcategoria Fisiológico.

A sub-categoria Feminilidade apresentou um maior número de respostas, mesmo comparando com as outras categorias Saúde, Limpeza, Ovulação e Boa/Ruim. Num levantamento realizado por SNOWDEN e CHRISTIAN(6) sobre as crenças das mulheres sobre sua menstruação, foi observado que este processo é considerado necessário para sua feminilidade, que vai ao encontro da sub-categoria Feminilidade e da categoria Normal utilizadas neste trabalho. Percebemos a importância da menstruação como uma condição para a sua existência como muIher, e ao mesmo tempo observa-se a aceitação da menstruação como uma imposição da própria natureza. Como exemplo uma das expressões das mulheres:

\section{...uma forma de sentir mulher \\ ...sem ela năo pode viver \\ ...deve ser da mulher, já nasceu para isso...}

É também expressada pelas mulheres como ritual de passagem, como sendo um ponto de partida para o início do ser mulher, onde a criança amadurece porque menstruou. Como exemplo de respostas das mulheres:

...começo da gente, quando passa de menina para moça...

Na sub-categoria Reproduçăo foram agrupadas $77(27 \%)$ respostas, relacionando a menstruação como uma forma de controle para a mulher saber se está grávida, além de proporcionar a capacidade de geração de filhos. Entre as respostas, as mulheres citam: 
as regras fazem a geração do filho, quando para, a mulher engravida.

A sub-categoria Fisiologico aparece com um número de respostas quase equivalente à subcategoria Reproduçăo, 76 (25,7\%). Verifica-se nesta sub-categoria, que a mulher tem noção de seu aparelho reprodutor, afirmando que sua menstruação está relacionada com codificações sofridas pelo ovário e útero. Entre as expressões as mulheres citam:

...É quando o ciclo da menstruaçăo termina, muda e começa a menstruaçăo.

...Sangramento que vem do útero e tem que sair.

Tabela 3: Distribuição das formas de expressão das mulheres sobre sua menstruação que foram incluídas na Categoria Saúde e suas sub-categorias. NAAM, São Paulo, 1993.

\begin{tabular}{l|l|r|r}
\hline CATEGORIA & SUB-CATEGORIA & \multicolumn{1}{|c|}{ No $^{\circ}$} & \multicolumn{1}{c}{$\%$} \\
\hline SAÚDE & INTEGRAL & 59 & 70,2 \\
\cline { 2 - 4 } & PARCIAL & 25 & 29,8 \\
TOTAL & & 84 & 100,0 \\
\hline
\end{tabular}

Conforme a tabela 3, a categoria Saúde apresenta um total de 84 (100\%) respostas. Esta categoria difere do referido no trabalho de SNOWDEN e CHRISTIAN(6) onde as mulheres vêm a menstruação como doença, enquanto que neste estudo as mulheres relacionam a presença da menstruação como saúde e a ausência desta como doença. Subdividimos esta categoria em Saúde integral e parcial.

A sub-categoria Integral aparece em destaque com um número de $59(70,2 \%)$, onde foram incluídas respostas relacionadas ao bem-estar integral ou do organismo como um todo, por exemplo:

...É a saúde da gente, se não descer

a gente fica doente

$\mathrm{Na}$ sub-categoria parcial, incluímos as respostas de $25(29,8 \%)$ mulheres que relacionaram a ausência da menstruação com danos à saúde, especificamente à saúde mental, como exemplo de citações de mulheres temos:

...Se nåo tem regra todo més fica lelé

...A menstruação vem porque se subir para a cabeça a pessoa pode ficar louca

O que nos chama a atenção, por ser este um conceito muito difundido em nossa cultura, através das gerações, onde as alterações da menstruação levariam a distúrbios mentais como a loucura.

Tabela 4: Distribuição dos conceitos das muIheres sobre sua menstruação inseridas na categoria Limpeza e suas sub-categorias. NAAM, São Paulo, 1993.

\begin{tabular}{l|l|r|r}
\hline CATEGORIA & SUB-CATEGORIA & \multicolumn{1}{|c|}{ N $^{\circ}$} & \multicolumn{1}{c}{$\%$} \\
\hline \multirow{2}{*}{ LIMPEZA } & GLOBAL & 68 & 88,3 \\
\cline { 2 - 4 } & LOCAL & 09 & 11,7 \\
\hline \multirow{2}{*}{ TOTAL } & 77 & 100,0 \\
\hline
\end{tabular}

Segundo SNOWDEN e CHRISTIAN(6), as mulheres vêem a menstruação como sujeira, no entanto, no presente estudo observamos que as mulheres expressam ser o produto de sua menstruação como sujeira, mas, o processo da menstruação em si, é visto como limpeza. Assim, conforme observamos na tabela 4 , a categoria Limpeza foi dividida em duas sub-categorias: Limpeza Global e Local. No que diz respeito à Limpeza Global encontramos $68(88,3 \%)$ respostas, onde as mulheres relacionam a menstruação como uma limpeza ou purificação do organismo. Como exemplo temos:

...Limpeza do organismo...

é a parte impura do sangue que é eliminada

Quanto à sub-categoria Limpeza Local encontramos $9(11,7 \%)$ mulheres que expressam ser a menstruação uma forma de limpeza de uma parte do corpo, mais especificamente o útero, como na resposta:

Sangue sujo que vem do útero...

Temos, ainda, a categoria Ovulação, onde observamos que $23(2,8 \%)$ mulheres relacionam a menstruação com a ovulação, demonstrando através de um conhecimento mesmo que vago, incompleto ou inadequado, que existe uma estreita relação da eliminação do sangue menstrual com a ovulação e ausência de fecundação, embora não consigam explicar o fenômeno em sua totalidade.

A categoria Boa/Ruim foi elaborada a partir das respostas de $13(1,6 \%)$ mulheres. Enquanto 
algumas colocam ser a menstruação uma coisa chata, que incomoda, outras encaram este mesmo acontecimento como algo bom para elas, mesmo que seja para servir de pretexto para livrá-las de uma situação aparentemente insatisfatória como na resposta:

...Dias que descansa do marido.

\section{CONSIDERAÇÕES FINAIS}

O estudo tornou possível verificar os conceitos próprios que as mulheres têm deste período e possibilitou inferir que alguns aspectos são congruentes com o conhecimento científico profissional. Assim sendo pudemos observar que $296(36,5 \%)$ mulheres consideram a menstruação como um acontecimento normal em sua vida e para a sua condição de mulher. Isto talvez explique os dados obtidos por TAKAGI, BENITES e SHINOHARA(7) onde um terço das muIheres que referem sintomas dolorosos da menstruação nada fazem para aliviá-los. Este fato nos leva a considerar que profissionais da área de saúde, especificamente, a enfermagem ligada à saúde da mulher, devam ter acesso à estes conceitos próprios, para que possam elaborar uma assistência de enfermagem de qualidade. Nesse sentido, o objetivo da assistência à saúde é de capacitar a mulher a desenvolver ações de autocuidado, respeitando suas crenças e valores dentro de sua própria cultura. Este estudo foi uma tentativa de compreensão dos dados encontrados, dentro desta perspectiva.

\section{REFERÊNCIAS BIBLIOGRÁFICAS}

1. BÍBLIA Sagrada. 9 ed. Săo Paulo: Paulinas, 1955. p.139: Levítico cap. 15 vers. 19 e 20.

2. BUCKLEY, T.; GOTTLIEB, A. Blood Magic: the Anthropology of menstruation. Berkeley: University of Califórnia Press, 1988. p.51-3: Menstrual images, meanings and values.

3. COMFORT, A. e COMFORT, J. ACB do Amore do Sexo: orientaçăo sexual pra adolescentes. Săo Paulo: Abril Cultural, 1980. p.38-9: Os marcos iniciais: menstruaça e ejaculaçăo.

4. FERREIRA, A.B. de H. Novo dicionário da língua portuguesa. Rio de Janeiro: Nova Fronteira, 1985. p. 768.
5. OREM, P.E. Nursing: concepts of practice. New York: Mc Graw Hill Book, 1985.

6. SNOWDEN, R. e CHRISTIAN, B. Pattems and perceptions of menstruation. Manuka: World Health Organization, 1983.

7. TAKAGI, A.M., BENITES, E.S. e SHINOHARA, M.Y. Estudos das açס̋es de autocuidado relativas a dismenorréia em mulheres de uma comunidade rural, 1991 (mimeo).

8. WEIL, P. Mistica do sexo. Belo Horizonte: Itatiaia, 1976. p.43-4.

Recebido para publicaçăo em 28.12 .93 


\section{ANEXO \\ ÁREA: HISTÓRICO DE SAÚDE DA MULHER}

\begin{tabular}{|c|c|}
\hline \multicolumn{2}{|c|}{ PARTE I: HISTÓRICO AUTO-EXPLICATIVO } \\
\hline \multicolumn{2}{|c|}{ 01.Nome: } \\
\hline \multicolumn{2}{|c|}{$\begin{array}{l}\text { Data de nasc.: } \_l-l- \\
\text { Ficha familia: }- \text { R.G.: }\end{array}$} \\
\hline \multicolumn{2}{|l|}{ 02. Ocupaçåo: } \\
\hline \multicolumn{2}{|l|}{ 03.Endereço: } \\
\hline \multicolumn{2}{|l|}{ Ponto de referência: } \\
\hline \multicolumn{2}{|l|}{ 04.Idade } \\
\hline Menos de 15 anos & ) \\
\hline De 15 a 25 anos & ) \\
\hline De 25 a 35 anos & ) \\
\hline De 36 a 45 anos & ) \\
\hline De 46 a 55 anos & ) \\
\hline De 56 a 65 anos & ) \\
\hline Mais de 66 anos & ) \\
\hline \multicolumn{2}{|l|}{ 05.Cor } \\
\hline Branca & ) \\
\hline Parda & ) \\
\hline Amarela & ) \\
\hline Preta & ) \\
\hline
\end{tabular}

06.Estado Civil

$\begin{array}{ll}\text { Solteira } & \text { ( ) } \\ \text { Casada } & (\text { ) } \\ \text { Desquitada } & \text { ( ) } \\ \text { Separada judicialmente } & (\text { ) } \\ \text { Divorciada } & (\text { ) } \\ \text { Separada } & (\text { ) } \\ \text { Viúva } & (\text { ) } \\ \text { Amasiada } & \text { ( ) } \\ \begin{array}{l}\text { (vive cl companheiro) } \\ \text { 07.Qual sua Religião? }\end{array}\end{array}$

08.Grau de Instrução (estudo)

Primeiro grau completo ( )

incompleto

Que série:

Segundo grau completo ( )

incompleto

Que série:
Universitário completo ( )

incompleto

Que série:

Analfabeto ( )

09. Quando desceram as primeiras Regras? (incômodo)

Antes dos 10 anos ( )

entre 10 e 12 anos ( )

entre 12 e 15 anos ( )

Após 15 anos ( )

Nunca apresentou ( )

10.De quanto em quanto tempo aparecem ou apareciam as Regras?

Uma vez entre 20 e 25 dias ( )

Uma vez entre 26 e 30 dias ( )

Uma vez entre 31 e 35 dias ( )

Uma vez em mais de 36 dias( )

De modo irregular

11. Quantos dias costuma ficar com as Regras?

Até 3 dias

De 3 a 6 dias

( )

De 6 a 10 dias

Mais de 10 dias

( )

()

( )

12. Quando foram suas últimas Regras?

Há menos de 1 mês ( )

Há mais de 1 mês ( )

Há mais de 2 meses ( )

Há mais de 4 meses ( )

Há mais de 6 meses ( )

Há mais de 1 ano ( )

Há mais de 2 anos ( )

Há mais de 5 anos ( )

Há mais de 10 anos ( )

13.A senhora acha que está grávida atualmente?

$\operatorname{Sim}($ ) Não ( )

14.A senhora apresentou algum sangramento por baixo, fora das regras nestes últimos tempos?

Sim ( ) Não ( ) Nãolembro ( ) 
15.Quando?

Há alguns dias

Há uma semana

( )

Há algumas semanas

( )

( )

Há um mês

( )

( )

( )

Há alguns meses

16. Quantas vezes?

Uma vez

Duas vezes

Três vezes

Mais de três vezes

( )

()

( )

( )

17.A senhora tem algum tipo de corrimento?

$\operatorname{Sim}($ ) Não ( )

18. Há quanto tempo?

Há 1 mês

Há mais de 2 meses

( )

Há mais de 4 meses

( )

Há mais de 6 meses

( )

Há 1 ano

19.De que cor é o corrimento?

$\begin{array}{ll}\text { Branco } & \text { ( ) } \\ \text { Amarelo } & \text { ( ) } \\ \text { Transparente } & \text { ( ) } \\ \text { Esverdeado } & \text { ( ) } \\ \text { Com sangue } & \text { ( ) } \\ \text { Outra cor } & \text { ( ) }\end{array}$

Qual:

20.Tem cheiro?

Sim ( ) Não( )

21. Tem sentido coceira nas partes de baixo?

$\operatorname{Sim}($ ) Não( )

22. Com que idade a senhora teve sua primeira relação sexual?

Antes dos 15 anos ( )

Entre 15 e 18 anos ( )

Após 18 anos

( )

23.Sente dor durante ou após uma relação sexual?

Sim( ) Não ( ) Às vezes ( )

24. Tem sangramento durante ou após uma relaçåo sexual?

$\operatorname{Sim}($ ) Não ( ) Às vezes ( )
25. Qual o número de vezes que a senhora costuma ter relações sexuais?

Várias vezes ao dia

1 vez por semana

( )

1 vez em quinze dias

1 vez em mais de

26. Quantos companheiros a senhora já teve?

Um

Dois

( )

Três ( )

Quatro ( )

Mais de cinco ( )

27.A senhora sente vontade de ter relações sexuais?

Sim ( ) Não ( ) Às vezes ( )

28.A senhora fica satisfeita após as relações sexuais?

Sim ( ) Não ( ) Às vezes ( )

29.A senhora usa algum destes métodos para evitar filhos?

Pílulas

( )

Diafragma

( )

DIU

( )

Geléias

( )

Protetor (camisinha) ( )

Nenhuma das anteriores ( )

Outros métodos

Quais:

30.Durante quanto tempo usa ou usou anticoncepcionais?

Há menos de 1 ano ( )

Um ano ( )

Dois anos ( )

Três anos ( )

Quatro anos ( )

Cinco anos ( )

Mais de cinco anos ( )

31.A senhora já esteve grávida alguma vez?

Sim ( ) Não ( ) Não sei ( )

32. Quantas vezes?

$\begin{array}{ll}\text { Uma ( ) } & \text { Seis ( ) } \\ \text { Duas ( ) } & \text { Sete ( ) } \\ \text { Três ( ) } & \text { Oito ( ) }\end{array}$


Quatro ( ) Nove ( )

Cinco ( Mais de nove ( )

33. Quantos filhos a senhora teve?

Nenhum ( ) Cinco ( )

Um ( ) Seis ( )

Dois ( ) Sete ( )

Três ( ) Oito ( )

Quatro ( ) Mais de oito ( )

34. Que tipos de parto a senhora teve?

Normal

( )

Cesariana

( )

Fórceps

( )

35.Com que idade teve seu primeiro filho?

Antes dos 15 anos ( )

Entre 15 e 18 anos ( )

Entre 18 e 30 anos ( )

Após os 30 anos ( )

36.Já provocou algum aborto?

Sim ( ) Não ( )

37. Quantos?

Um ( ) Três ( )

Dois ( ) Mais de três ( )

38. Como fez o aborto?

39.A senhora ou alguém da sua família teve ou tem alguma dessas doenças?

Diabetes $\quad \operatorname{Sim}($ ) Não ( )

Quem:

$\operatorname{Sim}($ )

Não ( )

Pressão alta $\quad \operatorname{Sim}($ ) Não ( )

Quem:

Não ( )

Problema no coração

$\operatorname{Sim}($ ) Não ( )

Quem:

Problema mental

$\operatorname{Sim}($ ) Não ( )

Quem:

Câncer

$\operatorname{Sim}($ ) Não ( )

Quem:

Outras. Qual:

Quem:

40.Alguém da sua família morreu por alguma dessas doenças?

Quem:

Qual doença:

41. A senhora trabalha fora de sua casa? (caso năo, não precisa responder às demias questőes)

$\operatorname{Sim}($ ) Não ( )

42. Quantas horas a senhora trabalha por dia?

Menos de 6 horas ( )

De 6 a 8 horas ( )

Mais de 8 horas ( )

43.0 que a senhora acha do seu trabalho?

Está satisfeita

( )

Sente-se pressionada ( )

Feliz

Pretende mudar ( )

Não gosta ( )

44.A senhora está exposta no seu trabalho?

À umidade

( )

À poeira

()

À radiação

( )

À fumaça

( )

A produtos químicos

()

Ao frio

Ao calor

()

Nenhuma das anteriores

( )

45. Observações: 
PARTE II: ENTREVISTA

01. Qual foi o motivo da última consulta médica?

02.Qual o motivo da consulta atual?

03. Cite os problemas de saúde que a senhora resolve sozinha:

04. Como costuma resolver estes problemas?

05. Quando tem problemas de saúde, além do médico, quais são as pessoas que você procura?

06. Você sente alguma coisa durante as Regras? O quê?

07. O que você faz para se sentir melhor nessas
ocasiőes?

08.0 que você acha que são as Regras?

09.Já fez algum tratamento para descer ạs Re- gras?

10. Você utiliza algum tratamento para o correimento? Qual?

11. O que a senhora acha do sangramento fora das Regras?

12. A senhora já apresentou alguma doença venérea? Fez tratamento?

13.A senhora utiliza drogas? Quais?

14.A senhora tem o hábito de beber e/ou fumar?

15. Condições atuais de saúde:

Repouso:

Sono:

Atividade física:

Hidratação:

Alimentação:

Higiene: 
PARTE III: EXAME FÍSICO

Nome:

R.G.:

Ficha Família:

Sinais vitais

T:

PA:

Cabeça/pescoço (gânglios, dor, tumoração):

\section{Mamas}

Aspecto da pele:

Dor:

Nódulos:

Secreção:

Outras alterações:

Auto-exame de mamas

Conhecimento, época do ciclo, mamilos:

Abdômen:

\section{Sistema geniturinário}

Queixas:

( ) Cistocele

( ) Retocele

( ) Disúria

( ) Polaciúria

( ) Intercorrências

( ) Outros
Quais:

Paredes vaginais:

\section{Secreções}

Aspecto:

Quantidade:

Odor:

Cor:

\section{Períneo}

( ) Íntegro

( ) Roto - Grau de rotura:

Presença de lesões:

Colo

Características macroscópicas:

Teste de Schiller

( ) Negativo ( ) Politivo

Impressão geral (postura quanto à participar na entrevista):

Intercorrências gerais observadas:

\section{Conduta:}

